Article

\title{
Influence of Chitosan Addition on Resorcinol-Formaldehyde Xerogel Structure
}

\author{
Ahmed Awadallah-F 1,2 and Shaheen A. Al-Muhtaseb 1,* (D) \\ 1 Department of Chemical Engineering, Qatar University, Doha P.O. Box 2713, Qatar; \\ ahmed.awadallah@qu.edu.qa \\ 2 Radiation Research of Polymer Department, National Centre for Radiation Research and Technology, \\ Atomic Energy Authority, Nasr City, Cairo P.O. Box 29, Egypt \\ * Correspondence: s.almuhtaseb@qu.edu.qa; Tel.: +974-4403-4139; Fax: +974-4403-4131
}

Received: 8 September 2019; Accepted: 16 October 2019; Published: 28 October 2019

\begin{abstract}
Gels are usually not environment-friendly due to their difficult biodegradability. Therefore, the addition of chitosan, even in small amounts, will make such gels biodegradable and thus can be useful in many applications that require environment-friendly materials. The addition of small quantities of chitosan to the reacting solution resorcinol-formaldehyde xerogel was investigated. Different hybrid resorcinol-formaldehyde-chitosan xerogels were characterized by different techniques, including Raman spectra, FTIR, XRD, TGA, SEM, surface area and porosity analyzer, and CHNS/O microanalyzer. It was seen that the addition of chitosan, even in a minor quantity, has a significant influence on the structural features of the resulting xerogels. The lattice order and crystallinity, chemical functions, thermal stability, morphology, elemental ratio, pore structure, and appearance were changed by adding chitosan into the xerogel structure.
\end{abstract}

Keywords: chitosan; resorcinol; formaldehyde; porous materials; gels; composites

\section{Introduction}

Chitin, which is biopolymer extracted from sea creatures including crustaceans of shrimps and crab shells, is the second most common polymer after cellulose on earth [1,2]. Chitosan (Cs) is considered a deacetylated derivative of chitin [3]. It is a biodegradable non-toxic natural polymer. Chitosan has some unique features such as biocompatibility, biodegradability, non-toxicity, and complexing with metal ions [4]. Therefore, it is exploited universally in various applications such as in pharmaceuticals [5], the food industry [6], and water remediation [7]. Furthermore, the surface groups, namely, hydroxyl and amino groups, contribute to the hydrophilicity and active adsorption sites of Cs [8]. Pekala introduced the polycondensation reaction of resorcinol (R) with formaldehyde (F) to form a xerogel $(X)$, which is named hereafter as RFX [9]. Xerogels are a kind of solid-formed gels, which are being synthesized through a slow drying process at room temperature with an unconstrained shrinkage [10]. The difference between aerogels and xerogels lies in the drying process, where the excess of solvent is extracted from the gel to obtain dry gels. Regarding aerogels, the solvent is removed by supercritical $\mathrm{CO}_{2}$ extraction, which is a tedious technique that preserves the hierarchy of the pore structure formed in the gelation process. On the other hand, removing the solvent by convective drying at ambient conditions results in xerogels. In the later case, the micropores are preserved whereas the macro- and mesopores could collapse depending on the mechanical strength of the gel [11]. Xerogels are considered to be excellent support materials for metal and non-metal functional groups, and are utilized broadly in fuel cells due to their ability to exhibit controlled structures and adjustable pore sizes as well as their good stability $[12,13]$. They are widely used in thermal insulation, nuclear particle detection, light guides, as wood adhesives, and electronic devices [14-18]. Kinnertová and Slovák [19] investigated 
the effect of catalyst amount on properties of RF xerogels and found that it has a significant effect on the pore structure. Pincipe et al. [20] studied the effects of various parameters on the properties of melamine-resorcinol-formaldehyde xerogels and confirmed that they have a significant influence on the gel formation and its pore structure.

Various studies in literature were mentioned that address mixing resorcinol-formaldehyde gels with different components. For instance, Alshrah et al. [21] reported that the addition of polyacrylonitrile nanofibers into resorcinol-formaldehyde aerogels enhanced their thermal conductivity and other properties. Grishechko et al. [22] investigated a mixed lignin-phenol-formaldehyde and found that the resulting pore-size distributions depended strongly on the initial composition, but not on the method of drying. Haghgoo et al. [23] studied the composite made of multi-walled carbon nanotubes with resorcinol-formaldehyde gels. The composite gels were synthesized by conducting the sol-gel reaction of resorcinol and formaldehyde in a suspension of carbon nanotubes in water, followed by $\mathrm{CO}_{2}$ supercritical drying.

Due to the importance and wide applications of both xerogels and chitosan, chitosan can import its unique features to xerogels and therefore widen their range of applications. Furthermore, the addition of chitosan to gels can make them more biodegradable and thus environment-friendly materials. The authors investigate here hybrid compounds of minor quantities of chitosan into RFX. Structure changes (such as lattice orders/defects, crystallinity, morphology, pore properties), thermal stability, chemical structure, and appearance of outcome hybrid products are investigated.

\section{Experimental}

\subsection{Materials}

Resorcinol (purity 99\%), formaldehyde (37 wt.\%) (from Sigma-Aldrich, Darmstadt, Germany), glacial acetic acid (assay 99.8\%, Analar, BDH, England), chitosan (medium molecular, Sigma-Aldrich, St. Louis, MO, USA), $\mathrm{Na}_{2} \mathrm{CO}_{3}$ (Fisher Scientific, Loughborough, UK), and ultrapure water (Elix ${ }^{\circledR} 70$ Purification System, Molsheim, France) were used. All reagents are used as received. The measured densities of the formaldehyde and acetic acid solutions were 1.257 and $1.207 \mathrm{~g} / \mathrm{cm}^{3}$, respectively. Scheme 1 shows the structures of chitosan, resorcinol, and formaldehyde.

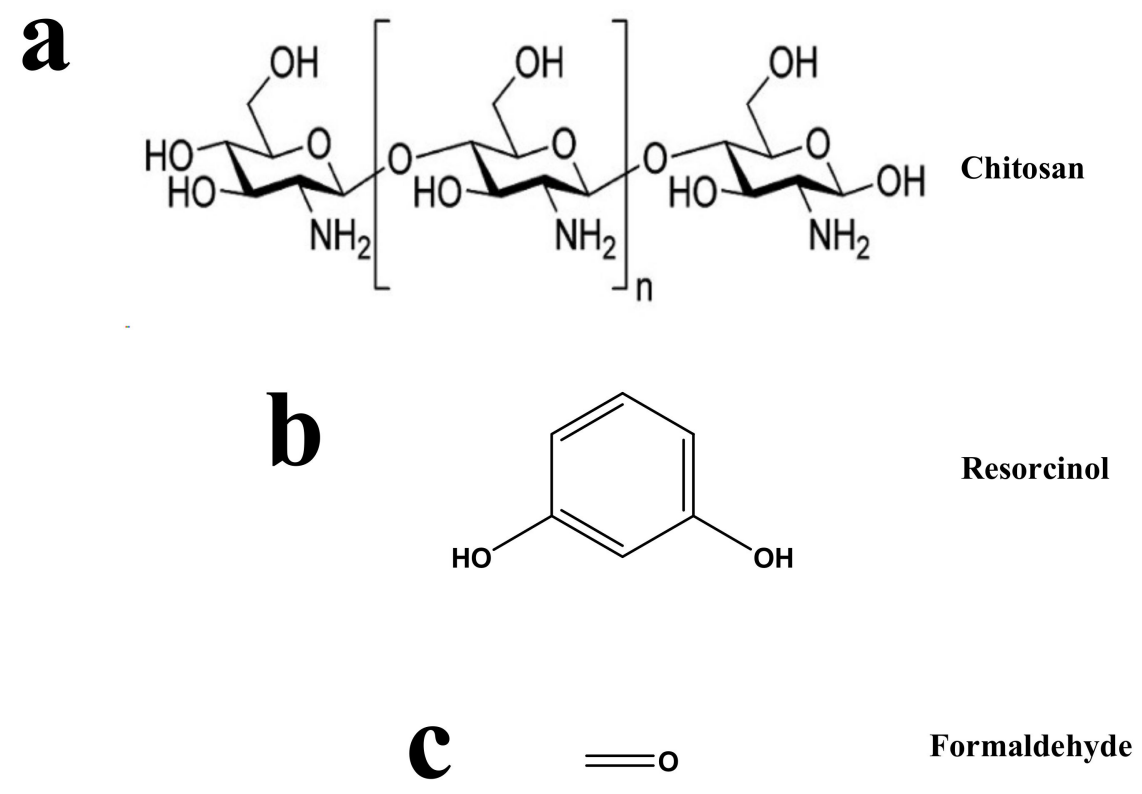

Scheme 1. Structures of (a) chitosan, (b) resorcinol, and (c) formaldehyde. 


\subsection{Synthesis of RFX with Chitosan}

Xerogels $(X)$ were synthesized from resorcinol (R), formaldehyde $(\mathrm{F})$, water $(\mathrm{W}), \mathrm{Na}_{2} \mathrm{CO}_{3}$ catalyst (C), and chitosan (Cs). A stock solution was prepared as $0.41 \mathrm{wt} . \%$ of Cs into acetic acid. R (12.44 g) and $\mathrm{C}(0.024 \mathrm{~g})$ were weighted and mixed with ultrapure water $(\mathrm{W})$, and then mixed with a suitable amount ( $\mathrm{x} \mathrm{mL}$, where $\mathrm{x}=0,1,2,3,4$, and $5 \mathrm{~mL}$ ) of Cs solution. The corresponding produced gels will be denoted as RFX-Cs-" $x$ ", where " $x$ " is the used volume of the Cs stock solution used (mL). The total volume of $\mathrm{W}$ and Cs stock solutions were fixed at $32.60 \mathrm{~mL}$, where an amount $(x \mathrm{~mL})$ of Cs stock solution corresponds to an amount $(32.60-x) \mathrm{mL}$ of $\mathrm{W}$. This mixture was stirred magnetically until all contents were fully dissolved, and then, $17.40 \mathrm{~mL}$ of $\mathrm{F}$ solution was added onto the dissolved reactants. The weight percentages of the above ingredients of the six xerogels (RFX-Cs-0 to RFX-Cs-5) are listed in Table 1.

Table 1. Composition (wt.\%) of starting solutions for the RFX-Cs-" $x$ " gel samples.

\begin{tabular}{ccccccc}
\hline$x$ & $\mathbf{R}$ & $\mathbf{F}$ & $\mathbf{W}$ & $\mathbf{C}$ & $\mathbf{C s}$ & Acetic Acid \\
\hline 0 & $18.585 \%$ & $32.676 \%$ & $48.703 \%$ & $0.036 \%$ & $0 \%$ & $0 \%$ \\
1 & $18.528 \%$ & $32.575 \%$ & $47.064 \%$ & $0.036 \%$ & $0.007 \%$ & $1.790 \%$ \\
2 & $18.471 \%$ & $32.475 \%$ & $45.434 \%$ & $0.036 \%$ & $0.015 \%$ & $3.569 \%$ \\
3 & $18.414 \%$ & $32.375 \%$ & $43.815 \%$ & $0.036 \%$ & $0.022 \%$ & $5.338 \%$ \\
4 & $18.358 \%$ & $32.277 \%$ & $42.205 \%$ & $0.035 \%$ & $0.029 \%$ & $7.095 \%$ \\
5 & $18.302 \%$ & $32.178 \%$ & $40.606 \%$ & $0.035 \%$ & $0.037 \%$ & $8.842 \%$ \\
\hline
\end{tabular}

After that, the solution $\mathrm{pH}$ value was adjusted at 5 by using diluted $\mathrm{HNO}_{3}$ and $\mathrm{NH}_{4} \mathrm{OH}$ buffers. $\mathrm{RF}$ solutions were then poured into polypropylene vials, sealed, and placed to cure in an oven at $50 \pm 1{ }^{\circ} \mathrm{C}$ for 7 days. To prohibit the dehydration of the gels, and to increase the crosslinking in produced products, $2 \%$ acetic acid solution was poured upon the gel surfaces after their solidification for 7 days. After the 7-day period, the cured samples were allowed to cool to room temperature. The remaining solutions above the cured gels were then decanted and exchanged with acetone at room temperature. The solvent exchange process was done by leaving the gels in acetone at room temperature for $24 \mathrm{~h}$, and replacing the remaining acetone daily with fresh acetone for 3 consecutive days. After the third day of solvent exchange, the cured gels and the accompanying fresh acetone were placed in an oven at $50 \pm 1{ }^{\circ} \mathrm{C}$ for 2 days to evaporate acetone completely [24].

\subsection{Characterization}

Fourier transform infrared (FTIR) spectroscopy (NICOLET, iS10, Thermo-Scientific) was used to confirm the structure of the prepared samples. FT-Raman spectra were estimated by a Bruker FT-Raman spectrometer of type RFS 100/S that is attached to a high resolution (better than $0.10 \mathrm{~cm}^{-1}$ ) Bruker-IFS 66/S spectrometer. The morphologies of RFX-Cs composite gels were observed with a FEI Nova $^{\mathrm{TM}}$ nanoscanning electron microscopy 450 (Nova NanoSEM). CHNS/O, Thermo Scientific FLASH 2000 Organic Elemental Analyzer (Melano, Italy) was used to determine the elemental compositions of the samples. Thermogravimetric analyses (TGA) were carried out using a PerkinElmer Pyris6 TGA analyzer under a flow of $\mathrm{N}_{2}$ gas in the range of 30 to $800^{\circ} \mathrm{C}$, with a heating rate of $10^{\circ} \mathrm{C} / \mathrm{min}$. X-ray diffraction (XRD) measurements were conducted by Miniflex II Benchtop XRD apparatus, manufactured by Rigaku Corporation, Japan. The $2 \theta$ scan data were collected at $0.05^{\circ}$ intervals over the range of 5 to $90^{\circ}$, and at a scan speed of $0.05^{\circ} / \mathrm{min}$. A Micromeritics ASAP2420 ${ }^{\circledR}$ accelerated surface area and porosimetry analyzer system, with an enhanced micropore capability (utilizing 1-Torr pressure transducer), was used to measure the pore structures of RFX-Cs-0, RFX-Cs-1, RFX-Cs-2, RFX-Cs-3, RFX-Cs-4, and RFX-Cs-5 samples using the adsorption isotherms of $\mathrm{N}_{2}$ at $77 \mathrm{~K}$. Prior to the adsorption measurements, the samples were regenerated in-situ for $24 \mathrm{~h}$ at a temperature of $473 \mathrm{~K}$ under vacuum $\left(1 \times 10^{-4} \mathrm{~Pa}\right)$. The pore structure properties were obtained by built-in calculations based on the density functional theory (DFT) [24]. 


\section{Results and Discussion}

Figure 1 shows the Raman (a) and FTIR (b, c) spectra for the six RFX-Cs samples. Figure 1a shows two characteristic Raman spectra peaks at 1355 and $1589 \mathrm{~cm}^{-1}$, which refer to disorder peak (D-band) and graphitic peak (G-band), respectively. The intensity ratio of the D-band to the G-band (i.e., $I_{D} / I_{G}$ ratio) helps to estimate the defects and disorders of RFX-Cs samples [25]. The results of $I_{D} / I_{G}$ ratios, along with CHNS/O analyses and pore characteristics of RFX-Cs-0 through RFX-Cs-5, are presented in Table 2. Overall, it is observed from Table 2 that increasing the concentration of Cs into RFX leads to increasing $I_{D} / I_{G}$ ratios, which indicates a significant increase of disorders and defects inside the structures of RFXs (even though the added amounts of Cs is very minor). Furthermore, increasing the concentration of Cs into the RFX results in slightly reducing concentrations of carbon and hydrogen, and slightly increasing concentration of nitrogen. The presence of Cs into RFX affects its pore structure, pore volume, surface area, crystal order/disorder, $\mathrm{N}_{2}$ adsorption capacity, and average pore width. Moreover, the data listed in Table 2 shows that the adsorption capacities of RFX-Cs- 1 and RFX-Cs-2 samples are low. This is due to lowering their total pore volumes.

Figure $1 \mathrm{~b}$ exposes the whole scale of FTIR spectra from 4000 to $400 \mathrm{~cm}^{-1}$, and Figure 1c shows a zoomed-in range from 1700 to $500 \mathrm{~cm}^{-1}$. The peaks at 2935, 2870, and $1477 \mathrm{~cm}^{-1}$ (related to the $\mathrm{CH}_{2}$ stretching and bending vibrations) were observed in RFX-Cs-0 (curve 1), but not in other samples. The broadband at $3302 \mathrm{~cm}^{-1}$ indicates the aromatic $\mathrm{OH}$ group of resorcinol, whereas that at $1607 \mathrm{~cm}^{-1}$ refers to the aromatic ring stretches. The medium-to-weak peak appearing at $1218 \mathrm{~cm}^{-1}$ refers to that of methylene ether linkages between resorcinol rings [26]. Curves 2 through 6 correspond to the presence of Cs into the matrix of RFX. The dotted blue lines crossing the peak at $\sim 1153 \mathrm{~cm}^{-1}$ is for asymmetric stretch of C-O-C, and that at $1298 \mathrm{~cm}^{-1}$ is for the C-N stretching vibration of type I amine. The peak at $1298 \mathrm{~cm}^{-1}$ that appeared for RFX-Cs-0 started to diminish and became shoulder peak when adding Cs into the structure of RFX. On the other hand, a new small peak appears at $995 \mathrm{~cm}^{-1}$ in curves 2 to 6 (crossed via dotted blue lines), which is not found in pure RFX (i.e., sample RFX-Cs-0, represented by curve 1). Therefore, changes occurred in the structure of RFX by adding Cs even in minor amounts.

Table 2. Summary of parameters derived from Raman spectra, surface area analyzer, and CHNS/O microanalyzer.

\begin{tabular}{|c|c|c|c|c|c|c|c|c|c|}
\hline \multirow[t]{2}{*}{ Sample } & \multirow[t]{2}{*}{$\left(I_{D} / I_{G}\right)^{a}$} & \multirow{2}{*}{$\begin{array}{l}V_{\text {Total }}^{\mathrm{b}} \\
\left(\mathrm{cm}^{3} / \mathrm{g}\right)\end{array}$} & \multirow{2}{*}{$\begin{array}{c}\mathrm{S}_{\text {Total }} \mathrm{b} \\
\left(\mathrm{m}^{2} / \mathrm{g}\right)\end{array}$} & \multirow{2}{*}{$\begin{array}{c}\text { Average } \\
\text { Particle Size } \\
\text { (nm) }\end{array}$} & \multirow{2}{*}{$\begin{array}{c}\text { Adsorption Capacity } \\
\text { of } \mathrm{N}_{2} \mathrm{~b} \text { at } 77 \mathrm{~K} \\
(\mathrm{mmol} / \mathrm{g})\end{array}$} & \multirow{2}{*}{$\begin{array}{l}\text { Average Pore } \\
\text { width }{ }^{b} \\
(\mathrm{~nm})\end{array}$} & \multicolumn{3}{|c|}{$\begin{array}{l}\text { Elemental Analysis } \\
(\%)\end{array}$} \\
\hline & & & & & & & $\mathrm{C}$ & H & $\mathbf{N}$ \\
\hline RFX-Cs-0 & 0.51 & $\begin{array}{l}\leq 93 \mathrm{~nm}^{\mathrm{c}} \\
=0.290\end{array}$ & $\begin{array}{l}\geq 1 \mathrm{~nm}^{\mathrm{d}} \\
\quad=138\end{array}$ & 112 & 8.97 & 4 & 62.07 & 5.51 & 0 \\
\hline RFX-Cs-1 & 0.65 & $\begin{array}{l}\leq 1 \mathrm{~nm}^{\mathrm{c}} \\
=9 \times 10^{-5}\end{array}$ & $\begin{array}{l}\geq 1 \mathrm{~nm}^{\mathrm{d}} \\
=0.03\end{array}$ & 20,221 & 0.03 & 1 & 60.70 & 5.23 & 0.09 \\
\hline RFX-Cs-2 & 0.70 & $\begin{aligned} & \leq 1 \mathrm{~nm}^{\mathrm{c}} \\
= & 24 \times 10^{-5}\end{aligned}$ & $\begin{array}{l}\geq 1 \mathrm{~nm}^{\mathrm{d}} \\
=0.189\end{array}$ & 7487 & 0.02 & 1 & 61.66 & 5.13 & 0.16 \\
\hline RFX-Cs-3 & 0.71 & $\begin{array}{l}\leq 186 \mathrm{~nm}^{\mathrm{c}} \\
=0.20\end{array}$ & $\begin{array}{l}\geq 68 \mathrm{~nm} \\
\mathrm{~d} \\
=6.146\end{array}$ & ND & 6.20 & 90 & 60.54 & 5.11 & 0.12 \\
\hline RFX-Cs-4 & 0.72 & $\begin{array}{l}\leq 400 \mathrm{~nm}^{\mathrm{c}} \\
\quad=0.07\end{array}$ & $\begin{array}{l}\geq 1 \mathrm{~nm}^{\mathrm{d}} \\
=17.61\end{array}$ & 2038 & 2.09 & 8 & 60.49 & 4.82 & 0.23 \\
\hline RFX-Cs-5 & 0.78 & $\begin{array}{l}\leq 217 \mathrm{~nm}^{\mathrm{c}} \\
\quad=0.21\end{array}$ & $\begin{array}{l}\geq 1 \mathrm{~nm}^{\mathrm{d}} \\
=48.23\end{array}$ & 482 & 5.49 & 9 & 59.80 & 4.68 & 0.24 \\
\hline
\end{tabular}

${ }^{a}$ values determined from Raman spectra. ${ }^{b}$ Values determined from Micromeritics ASAP ${ }^{\circledR} 2420$ measurements. ${ }^{c}$ Pore volume measurements obtained from Micromeritics ASAP ${ }^{\circledR} 2420$ analyzer are given for pores less than this size. ${ }^{d}$ Surface area measurements obtained from Micromeritics $A S A P^{\circledR} 2420$ analyzer are given for pores beyond this size. 

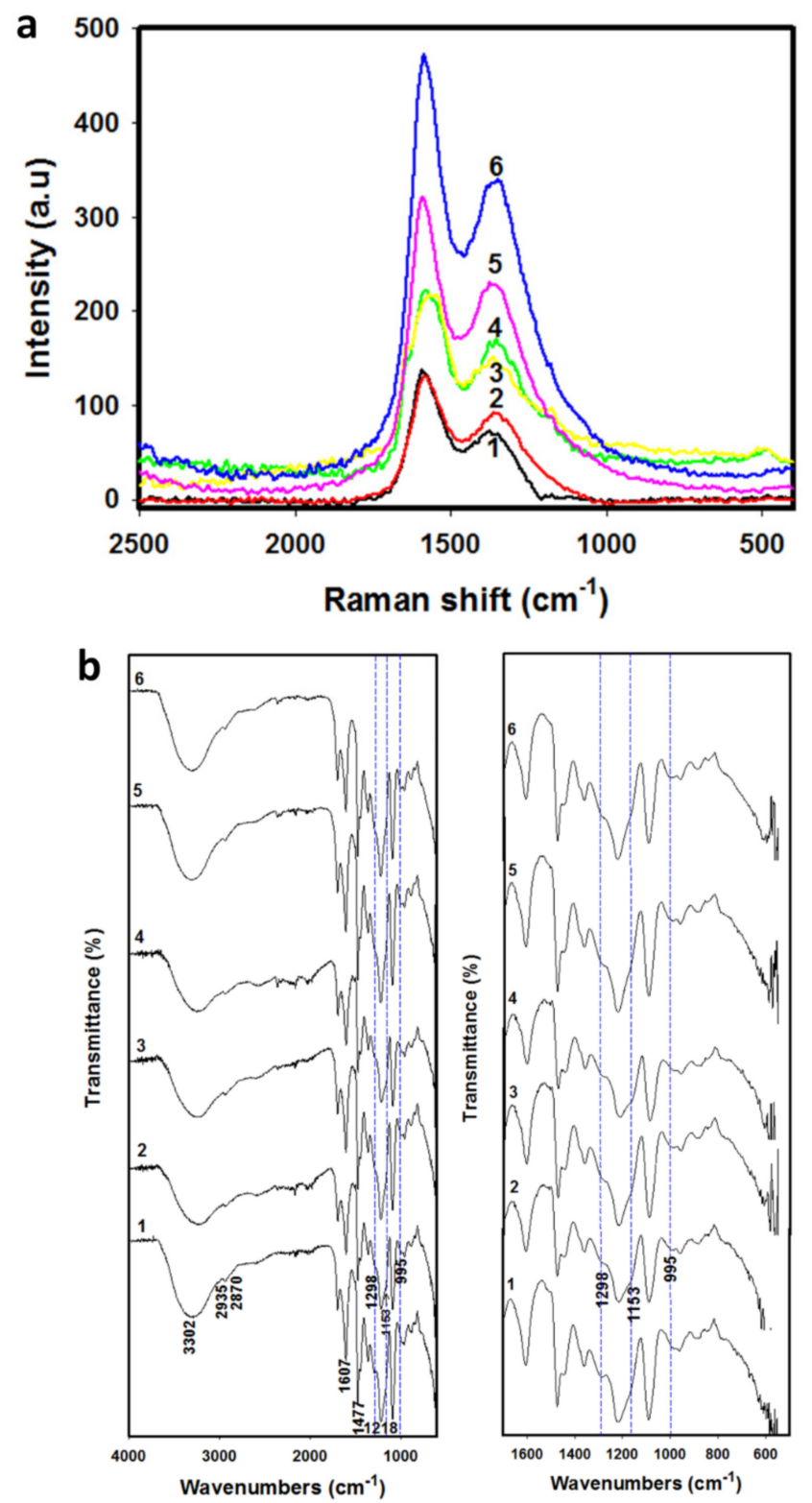

Figure 1. (a) Raman and (b, c) FTIR spectra of Cs-RFX hybrid samples RFX-Cs-0 through RFX-Cs-5 (curves 1 through 6, respectively). FTIR spectra in figure (b) range from $4000-400 \mathrm{~cm}^{-1}$ and in subfigure (c) range from $1700-500 \mathrm{~cm}^{-1}$.

Figure 2a,b exhibits the XRD patterns and TGA thermograms, respectively, for the six RFX-Cs samples. In Figure 2a, the full width at half-maximum (FWHM) peeks of XRD profiles was used. It was observed that the intensity of XRD peaks decreases by adding Cs to the RFX. For instance, the intensity decreased from 1998 to 1480 cps when comparing RFX-Cs-0 to RFX-Cs-5, respectively, which corresponds to a decrease of $\sim 26 \%$ in intensity. This observation aligns with the Raman results, which indicate an increasing disorder with the addition of Cs into the RFX-Cs matrix. Furthermore, the XRD peak of RFX-Cs- 0 at $15.89^{\circ}$ shifts gradually to $19.75^{\circ}$ for RFX-CS- 5 . This shift is due to the insertion of $\mathrm{Cs}$ into the RFX matrix. Figure $2 \mathrm{~b}$ exposes that the presence of $\mathrm{Cs}$ into the RFX matrix affects the thermal stability noticeably. Overall, the increasing presence of Cs in the RFX structure decreases its thermal stability, which could be attributed to the already observed increasing disorder or defects. 

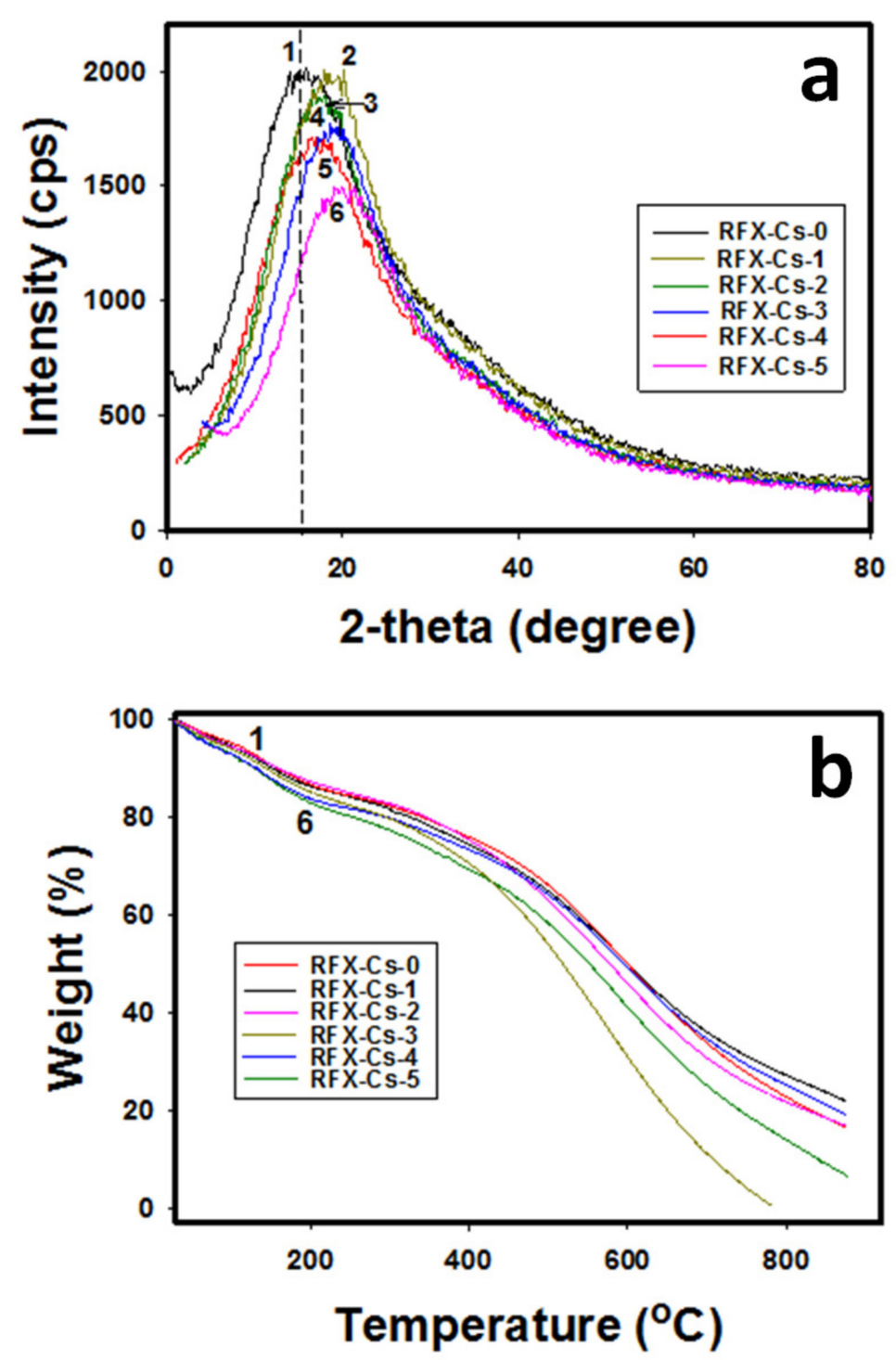

Figure 2. (a) XRD patterns and (b) TGA thermograms of the samples RFX-Cs-0 through RFX-Cs-5 (curves 1 through 6, respectively).

Figure 3a,b illustrates the optical photographs and SEM photomicrographs of the six RFX-Cs samples. It was observed from Figure $3 a$ that the color of samples changes gradually from an almost black color for RFX-Cs-0 to a pale yellow color for RFX-Cs-5. This can be attributed to the increasing distance between RF cross-linked segments upon the inclusion of Cs. Further, it was observed that the samples with higher Cs content exhibited less shrinkage than those of low Cs content upon drying.

Figure $3 \mathrm{~b}$ shows that RFX-Cs-3 (image 4 ) has a distinct topography that starts to form microspheres of RFX-Cs gel rather than interconnected lumps of samples RFX-Cs-0 through RFX-Cs-2 (image 1 through 3 , respectively). On the other hand, noticeable changes appear between the morphologies of RFX-Cs-3 and RFX-Cs-4 samples (images 4 and 5, respectively). This could indicate a critical composition between these two samples whereas the behavior changes considerably, which is worthy of future investigations. Samples RFX-Cs-4 and RFX-Cs-5 (images 5 and 6) show more voids between in the matrix of the gel, which is consistent with the observation obtained from Figure 3a. Therefore, the presence of Cs into the matrix of RFX samples has a significant effect on both the visual and morphological properties of the resulting hybrid RFX-Cs gels. 


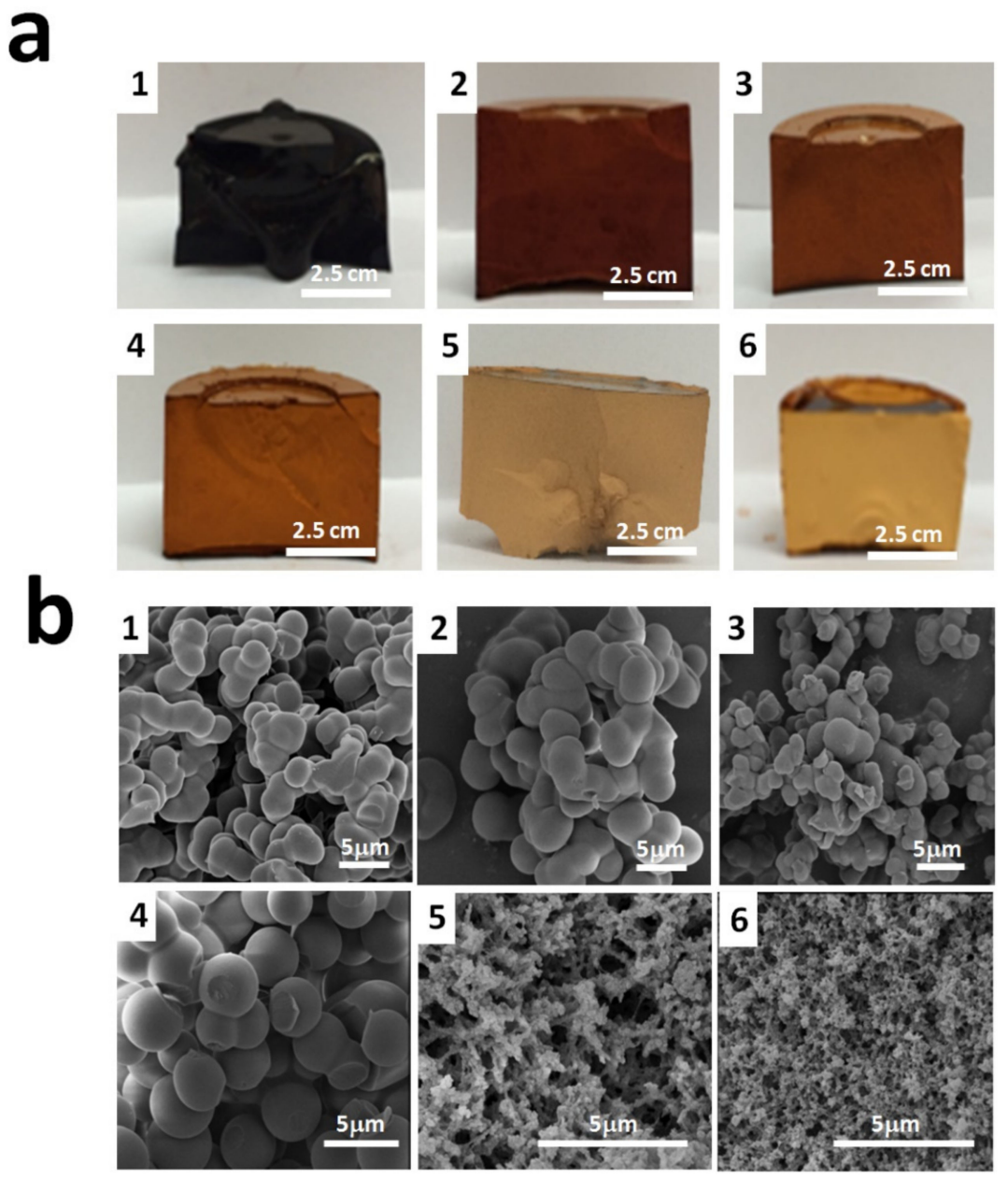

Figure 3. (a) Optical photos and (b) SEM photomicrographs of RFX-Cs-0 through RFX-Cs-5 samples (numbered as 1 through 6, respectively).

\section{Conclusions}

The impact of adding chitosan (Cs) into resorcinol-formaldehyde xerogel (RFX) structures upon their synthesis was studied. The properties of different samples were characterized by Raman spectra, FTIR, XRD, TGA, SEM, surface area and porosity analyzer, and CHNS/O microanalyzer. The results showed that, even though the Cs amounts added are minor, they have a significant effect on the RFX matrix. This impact led to clear changes on the features of gels formed (such as structure order, structure functions, crystallinity, elemental composition, morphology, pore structure, and optical appearances). Moreover, the Cs-embedded gels are more biodegradable and thus can be utilized for applications that require such environment-friendly materials. This includes, but is not limited to, the encapsulation and controlled release of bioactive compounds, biomedical fields, and tissue engineering. Other applications include packaging and thermal insulation tools, and as templates for the fabrication of new functional materials. Therefore, this study turns the spotlight on Cs-embedded gels that have potential to be developed as new advanced materials for various applications.

Author Contributions: Conceptualization, A.A.-F. and S.A.A.-M.; methodology, A.A.-F. and S.A.A.-M.; validation, A.A.-F. and S.A.A.-M.; formal analysis, A.A.-F.; investigation, A.A.-F.; resources, S.A.A.-M.; data curation, A.A.-F.; writing-original draft preparation, A.A.-F.; writing-review and editing, S.A.A.-M.; visualization, A.A.-F. and S.A.A.-M.; supervision, S.A.A.-M.; project administration, S.A.A.-M.; funding acquisition, S.A.A.-M.

Funding: Qatar National Research Fund (QNRF), Qatar.

Acknowledgments: This publication was made possible by the NPRP award (NPRP 08-014-2-003) from the Qatar National Research Fund (a member of Qatar Foundation). Statements made herein are the sole responsibility of 
the authors. Technical support from the Department of Chemical Engineering, Central Laboratory Unit (CLU) and Gas Processing Centre (GPC) at Qatar University is also acknowledged. Further, the publication of this article was funded by the Qatar National Library.

Conflicts of Interest: The authors declare no conflict of interest.

\section{References}

1. Yang, F.; Cai, M.-L.; Chen, W.; Bai, Z.-W. Performances comparison of enantiomeric separation materials prepared from shrimp and crab shells. Carbohydr. Polym. 2019, 204, 238-246. [CrossRef] [PubMed]

2. El Knidri, H.; Belaabed, R.; Addaou, A.; Laajeb, A. Lahsini, Extraction, chemical modification and characterization of chitin and chitosan. Int. J. Biol. Macromol. 2018, 120, 1181-1189. [CrossRef] [PubMed]

3. Shariatinia, Z. Pharmaceutical applications of chitosan. Adv. Colloid Interface Sci. 2019, 263, $131-194$. [CrossRef]

4. Samar, M.M.; El-Kalyoubi, M.H.; Khalaf, M.M.; Abd El-Razik, M.M. Physicochemical, functional, antioxidant and antibacterial properties of chitosan extracted from shrimp wastes by microwave technique. Ann. Agric. Sci. 2013, 58, 33-41. [CrossRef]

5. Jommanee, N.; Chanthad, C.; Manokruang, K. Preparation of injectable hydrogels from temperature and $\mathrm{pH}$ responsive grafted chitosan with tuned gelation temperature suitable for tumor acidic environment. Carbohydr. Polym. 2018, 198, 486-494. [CrossRef] [PubMed]

6. Khan, I.; Tango, C.N.; Miskeen, S.; Oh, D.-H. Evaluation of nisin-loaded chitosan-monomethyl fumaric acid nanoparticles as a direct food additive. Carbohydr. Polym. 2018, 184, 100-107. [CrossRef] [PubMed]

7. Bertoni, F.A.; González, J.C.; García, S.L.; Sala, L.F.; Bellú, S.E. Application of chitosan in removal of molybdate ions from contaminated water and groundwater. Carbohydr. Polym. 2018, 180, 55-62. [CrossRef]

8. Tan, W.; Zhang, J.; Zhao, X.; Dong, F.; Li, Q.; Guo, Z. Synthesis and antioxidant action of chitosan derivatives with amino-containing groups via azide-alkyne click reaction and $N$-methylation. Carbohydr. Polym. 2018, 199, 583-592. [CrossRef]

9. Pekala, R.W. Organic aerogels from the polycondensation of resorcinol with formaldehyde. J. Mater. Sci. 1989, 24, 3221-3227. [CrossRef]

10. Czarnobaj, K.; Czarnobaj, J. Sol-gel processed porous silica carriers for the controlled release of diclofenac diethylamine. J. Biomed. Mater. Res. 2008, 87B, 114-120. [CrossRef]

11. Al-Muhtaseb, S.A.; Ritter, J.A. Preparation and properties of resorcinol-formaldehyde organic and carbon gels. Adv. Mater. 2003, 15, 101-114. [CrossRef]

12. Thapaa, B.S.; Seetharamanb, S.; Chettyb, R.; Chandra, T.S. Xerogel based catalyst for improved cathode performance in microbial fuel cells. Enzym. Microb. Technol. 2019, 124,1-8. [CrossRef] [PubMed]

13. Kraiwattanawong, K. Improvement of the textural properties of templated carbon xerogels using cotton fibres as a hard template dehydrated by sulphuric acid. Diam. Relat. Mater. 2019, 92, 9-17. [CrossRef]

14. Hrubesh, L.W. Aerogel applications. J. Non-Cryst. Solids 1998, 225, 335-342. [CrossRef]

15. Zhou, J.; Ji, Y.; He, J.; Zhang, C.; Zhao, G. Enhanced mesoporosity and capacitance property of spherical carbon aerogel prepared by associating $\mathrm{Mg}(\mathrm{OH})_{2}$ with non-ionic surfactant. Microporous Mesoporous Mater. 2008, 114, 424-430. [CrossRef]

16. Attiaa, S.M.; Ismail, W.I.A.; Mossad, M.M. Characterization of pure and composite resorcinol formaldehyde aerogels doped with copper. Egypt. J. Phys. 2017, 45, 11-22. [CrossRef]

17. Li, T.; Cao, M.; Liang, J.; Xie, X.; Du, G. Mechanism of Base-Catalyzed Resorcinol-Formaldehyde and Phenol-Resorcinol-Formaldehyde Condensation Reactions: A Theoretical Study. Polymers 2017, 9, 426. [CrossRef]

18. Chen, F.; Xu, M.; Wang, L.; Li, J. Preparation and characterization of organic aerogels from a lignin-resorcinol-formaldehyde copolymer. BioResources 2011, 6, 1262-1272.

19. Kinnertová, E.; Slovák, V. Influence of catalyst amount on properties of resorcinol-formaldehyde xerogels. Thermochim. Acta 2018, 660, 37-43. [CrossRef]

20. Rincipe, I.A.; Fletcher, A.J. Parametric study of factors affecting melamine-resorcinol-formaldehyde xerogels properties. Mater. Today 2018, 7, 5-14.

21. Alshrah, M.; Naguib, H.E.; Park, C.B. Reinforced resorcinol formaldehyde aerogel with Co-assembled polyacrylonitrile nanofibers and graphene oxide nanosheets. Mater. Des. 2018, 151, 154-163. [CrossRef] 
22. Rishechko, L.I.; Amaral-Labat, G.; Szczurek, A.; Fierro, V.; Kuznetsov, B.N.; Celzard, A. Lignin—phenol—formaldehyde aerogels and cryogels. Microporous Mesoporous Mater. 2013, 168, $19-29$. [CrossRef]

23. Haghgoo, M.; Yousefi, A.A.; Mehr, M.J.Z.; Celzard, A.; Fierro, V.; Léonard, A.F.; Léonard, A.; Job, N. Characterization of multi-walled carbon nanotube dispersion in resorcinol-formaldehyde aerogels. Microporous Mesoporous Mater. 2014, 184, 97-104. [CrossRef]

24. Wadallah-F, A.; Elkhatat, A.M.; Al-Muhtaseb, S.A. Impact of synthesis conditions on meso- and macropore structures of resorcinol-Formaldehyde xerogels. J. Mater. Sci. 2011, 46, 7760-7769. [CrossRef]

25. Palaniselvam, T.; Aiyappa, H.B.; Kurungot, S. An efficient oxygen reduction electrocatalyst from graphene by simultaneously generating pores and nitrogen doped active sites. J. Mater. Chem. 2012, 22, 23799-23805. [CrossRef]

26. Mulik, S.; Sotiriou-Leventis, C.; Leventis, N. Time-efficient acid-catalyzed synthesis of resorcinol-formaldehyde aerogels. Chem. Mater. 2007, 19, 6138-6144. [CrossRef]

C 2019 by the authors. Licensee MDPI, Basel, Switzerland. This article is an open access article distributed under the terms and conditions of the Creative Commons Attribution (CC BY) license (http://creativecommons.org/licenses/by/4.0/). 